\title{
O passivo do lazer ativo
}

Giuliano Gomes de Assis Pimentel

\begin{abstract}
Resumo: O termo lazer ativo vem sendo utilizado para significar a atividade física no tempo livre. Este texto trata do julgamento crítico de tal categoria a partir dos seguintes recortes: os ditos e escritos sobre o lazer ativo no universo acadêmico; sua relação com o positivismo e o funcionalismo; a ramificação do termo na rede de práticas e discursos biomédicos de controle do tempo livre da população.
\end{abstract}

Palavras-chave: Atividades de lazer. Saúde. Poder

\section{INTRODUÇÃo}

Ao tratar da qualidade de vida é inevitável que especialistas usem os meios de comunicação (ou por eles sejam usados) para recomendar uma série de comportamentos e indicar certas condições como primordiais para se ter um bem-estar, uma vida melhor. Desta forma, o discurso hegemônico sobre qualidade de vida repousa sobre a idéia de estilo de vida individual (não fumar, realizar exercícios, controlar o estresse, entre outras medidas) e sobre determinações estruturais (a exemplo de hospitais, transporte, segurança, espaços de lazer ativo e controle da poluição).

O comportamento ativo (fisicamente) no tempo livre passa a ser visto como um dos componentes de melhoria da qualidade de vida, de tal forma que se pode até especular sobre uma perspectiva neo-higienista do lazer. De fato, podem ser relacionados autores e entidades que fazem defesas e proposições do lazer ativo na

"Centro de Ciências Biológicas. Departamento de Educação Física. Universidade Estadual de Maringá. Maringá, PR, Brasil. E-mail: ggapimentel@uem.br 
promoção da saúde (GUEDES et al, 2001; GURGEL, 2002; MANIFESTO..., 2003; TUBINO, 2007; NAHAS et. al., 2010).

Colado à concepção de "vida ativa", o discurso do "lazer ativo" prega a adesão à atividade física no tempo livre como uma forma de manutenção da saúde, especialmente na prevenção de doenças crônico-degenerativas e diminuição do estresse. Tal entendimento é disseminado desde artigos publicitários até periódicos específicos da classe médica, mas é especialmente difundido em programas massivos de atividade física. Entre as repercussões ideológicas e profissionais da veiculação de informações sobre os benefícios à saúde da vida ativa e os malefícios do sedentarismo, há a reverberação de recomendações sistematizadas sobre como ter uma existência saudável no conjunto das políticas públicas e das estratégias físico-sanitárias de instituições paraestatais (FRAGA, 2006).

Dada essa problemática mais ampla, este artigo dialoga com o entendimento de "lazer ativo" na produção brasileira. Esse termo, internacionalmente corrente nos anos 1950, é resgatado na última década para se referir à atividade física no tempo livre, tendo sua aplicação para além da comunidade específica do lazer. Os recortes para o debate são: a) os ditos e escritos sobre o lazer ativo no universo acadêmico; b) sua relação com o positivismo e o funcionalismo; c) a relação do termo com a rede de discursos e práticas biomédicos de controle do tempo livre da população.

\section{UMA RAZÃo de SER}

O lazer ativo não surge como uma ideia banal ou obsoleta. Ela deriva justamente da premissa de que se o tempo livre pode sediar alguns desvios ao status quo, o lazer pode servir de mecanismo de resgatar esses corpos à fisiologia do sistema. Esse preceito tem por base o funcionalismo, corrente de pensamento que "supõe que todas as esferas da vida desempenham alguma função social, sempre no sentido de garantir a harmonia, coesão e estabilidade do sistema" (DIAS, 2011, p. 45). Dado o funcionalismo focar as sociedades 
contemporâneas em função do processo de industrialização, o lazer acaba por ser uma derivação dessa sociedade industrial, funcionando para a integração social à ordem pré-estabelecida.

Visando contribuir à inserção produtiva do trabalhador na sociedade, a função do lazer ativo é enfrentar o crescimento das doenças crônico-degenerativas, fenômeno característico de sociedades industrializadas. A automação do trabalho e as comodidades civilizatórias, remetidas à racionalidade e à capacidade do capitalismo em prover a sociedade de mercadorias, diminuíram o nível de atividade física. Em complemento, o sedentarismo e o consumo de alimentação rica em gorduras e carboidratos também contribuem para o agravamento dessas doenças ligadas ao modo de vida urbano-industrial. Entre os efeitos dessa disfunção está o significativo o impacto econômico, especialmente no tocante ao tratamento médico, perda de produtividade e abstenção ao trabalho. (SILVA et. al., 2011)

O problema da inatividade física tende a ampliar-se também para a infância conforme Guedes et. al. (2001, p. 51). Segundo os autores, o movimentar-se nessa fase da vida se caracterizaria como uma "tendência inata", mas os estímulos do meio têm levado as crianças a se identifiquem com "atitudes sedentárias". Citam como exemplo, o "longo tempo de assistência à TV e ao vídeo, por não serem apresentadas outras opções de lazer". Logo, caberia à Educação Física promover meios necessários ao lazer ativo, visando a recuperação da saúde das crianças e seu retorno à sua condição natural de movimentos corporais.

Tanto no diagnóstico/prognóstico dado ao adulto trabalhador ou às crianças, parece se tomar como premissa que o consumo muitas vezes fetichista- de tecnologias de conforto (e, em amplitude maior, o sistema) não pode ser mudado, mas apenas ajustado. Nesse sentido, o reequilíbrio (frente às ameaças do sedentarismo) se dará no tempo livre, quando as pessoas poderão se motivar e aderir a práticas de lazer com consumo energético superior ao de repouso. Trata-se, portanto, de tornar o lazer um foco de atenção à manutenção funcional dos corpos, por meio de atividade física. 
Nahas (2005, p. 08) toma o lazer ativo "[...] como sendo um estilo de vida em que a atividade física é valorizada e integrada na vida diária, com ênfase no lazer". Lazer ativo é também o nome empregado a um programa de atividade física do Serviço Social da Indústria do estado de Santa Catarina, sob a consultoria desse autor. Como situa Nahas (2005, p. 5) "[...] o SESI/SC resolveu pegar este conceito e transferi-lo para as ações que já desenvolvia e estabelecer novas ações dentro deste princípio. Passou a ser um programa de promoção de um estilo de vida ativo e saudável, por conseqüência, para o trabalhador da indústria e seus familiares".

Eis, pois, não uma categoria inerte, sossegada sobre um academicismo diletante. O lazer ativo ressurge como ferramenta completa, voltada ao pensamento e à ação. Mas além de ser propositivo, com base em evidências epidemiológicas, o conceito também assume uma dimensão negativa na medida em que foi formulado com vistas a combater sua sombra, o par dialético contra o qual sua identidade se afirma: o lazer passivo.

O significado do que seja passivo no lazer é alvo de reflexões divergentes. No campo da abordagem biológica da saúde, ele é tomado como as práticas com baixo gasto de esforço corporal; na abordagem sociocultural seria a exposição alienada do indivíduo ao consumismo. Nele não é possível que o ócio seja criativo, sendo um indicativo - por exemplo - das crianças não terem brincadeiras saudáveis como antigamente ou da pouca adesão/aderência ao exercício físico no tempo livre ${ }^{1}$.

Cabe, portanto, à Educação Física a missão de tornar as pessoas ativas quando o lazer passivo é a hegemonia, pelos problemas que causa à saúde. Assim, "o grande desafio para nós, promotores da atividade física, promotores da saúde, por mudanças no estilo de

\footnotetext{
${ }^{1}$ Vale considerar a oscilação do termo lazer ativo não somente conforme a disciplina ou o olhar que faz uso desse vocábulo, mas também as variações ao longo do tempo e do espaço. A fim de confrontar a polissemia noutras perspectivas, recomendo a leitura de Dumazedier (1976), que abandona o termo nos anos 1960 por considerar que todo lazer -como atividade- é ativo, até autores mais contemporâneos que resignificam o termo, a exemplo de Backman e Crompton (1990) ou Csikszentmihalyi (1999).
} 
vida, é exatamente promover o que chamamos de lazer ativo numa sociedade que se transformou num verdadeiro paraíso do lazer passivo" (NAHAS, 2005, p. 11).

Já há entre estudiosos do lazer, algum esforço em situar a relatividade e a incongruência do termo. Melo (2005), por exemplo, toma o cinema, prática que embora não exija o gasto de muitas calorias, pode depreender um esforço significativo de compreensão. $\mathrm{O}$ autor critica que, mesmo nas Artes, existe uma divisão -elitistaentre expectador passivo e ativo, sendo que, do ponto de vista da educação desse sujeito, o ideal seria uma postura intermediária, o qual teria uma postura crítica frente aos filmes.

Dessa discussão, a atribuição de valores negativos ao lazer tomado como passivo, remete à necessidade de encontrar um sentido para o lazer. Por sua vez, ele precisa cumprir uma função, dentro de uma moral, para que esse sentido se realize. Pese-se o lazer necessitar não apenas funcionar para algo, mas, como prática social, essa função precisar desempenhar 'algo bom' e, mais precisamente, o bem (da sociedade) sob o perigo de depreciar-se para o mal, no caso, o lazer passivo, relacionado ao gasto com doenças e à decadência moral. Dado esse entendimento possível, passamos a discutir as ideologias e práticas que recortam o debate sobre lazer ativo.

\section{As IDEOLOGIAS E TEORIAS DE BASE}

Um aspecto a ser investigado com profundidade é a visão de causalidade em relação ao de moralidade. Termos como lazer ativo, e sua correspondente função de livrar as pessoas do sedentarismo e promover a saúde, nos levam a interrogar o grau de penetração de valores morais e religiosos nesse conceito. Vejamos: segundo Hood (2010), embora a vida seja fruto do acaso, o cérebro humano é programado para buscar ordem no mundo. Se a menta humana é acostumada a pensar em padrões, ela pode criá-los quando não 
encontra nenhum. Essa busca por sentido em meio à complexidade de fatores pode resultar em criações mentais pseudocientíficas, como buscar uma razão moral que organize a vida, o que pode levar concepções científicas a se misturarem com valorações.

A esse respeito, Helman (2003) postula que, na história ocidental, se produzem discursos e versões medicalizadas cuja mensagem de fundo reproduz leituras morais. A autora exemplifica com as representações coletivas, perpetradas na medicina, sobre as causas da obesidade. A falta de vontade ou a fraqueza de espírito estariam como fonte dos males, individualizando a vítima como culpada. As reflexões sobre esse tema apontam que o diagnóstico causal sobre comer muito e exercita-se pouco seria tradução contemporânea de alguns pecados capitais. Na raiz da questão reitera-se a desaprovação moral da gula e da preguiça, assim como da falta de autocontrole.

Courtine (1995) a respeito da genealogia religião-saúdecomércio na sociedade norte-americana, vê nos cuidados com o corpo o contrário do hedonismo, visto que emagrecer e aumentar a massa muscular é um trabalho de mortificação, pura ascese. Nesse sentido, o puritanismo vai pregar que cada pessoa é responsável por sua salvação, sendo necessário uma conversão também corporal, pois cuidar do próprio corpo é um elemento da salvação da alma. A atenção moral dirigida à saúde é ainda completada pelo capitalismo, o qual oferece procedimentos e mercadorias para se alcançar esse propósito.

Nesse tocante, o lazer começa a sofrer uma cisão entre os prazeres dispendiosos e os investimentos virtuosos. Os prazeres relacionados ao pecado têm uma consequência conhecida: a morte. Assim, o sexo sem segurança levará à 'peste gay' e o sedentarismo à obesidade, sinais que se projetam no corpo do denegrido. Já os investimentos nos cuidados com o corpo e alma são representativos do Homem de ação. Se as atividades físicas não levam a Deus, ao menos fornecem uma educação moral, favorecendo "os hábitos de ordem, de exatidão, de disciplina, essenciais ao bom funcionamento de uma sociedade industrial e burocrática" (COURTINE, 1995, p. 93). 
Uma reflexão inevitável quando se identifica o moralismo como pedra de arrimo desse processo de adjetivação do lazer em ativo (bom) versus o passivo (mal) é o questionamento do próprio sentido do lazer como categoria.

As categorias, via de regra, são ferramentas úteis ao pensamento, pois, por meio delas, é possível objetivar certos fenômenos, ampliando nossa capacidade analítica sobre eles. Por outro lado, cada categoria está associada a uma escola de pensamento, estando associada a um intricado sistema de se conhecer a realidade. A questão é que todo processo de conhecimento produz também aquilo que vai ser desconhecido nesse processo. Aignorância precisa ser compreendida como implicada no conhecimento. A resistência tem sua dimensão individual e psicológica, mas, também, cultural. Como pondera Foucault (2002) há objetos que se tornam inacessíveis ao pensamento dentro de uma determinada episteme, pois, em sua lógica interna, há coisas sujeitas a serem pensadas e ditas e outras que fogem ao quadro de referências dado por esse campo.

Há algo de podre no campo do lazer. Pode-se acreditar que o problema esteja nas práticas sociais, tendo em vista a decadência dos costumes no tempo livre. Termos cunhados nos últimos 50 anos trazem à tona a preocupação do mundo acadêmico com a perversão do lazer, o desvio de sua função. Para tanto, o lazer adjetivado vem nos alertar sobre os perigos ocultos no e do lazer: antilazer, semilazer, mercolazer, lazer não-sério, lazer anormal, lazer passivo (PIMENTEL, 2010). Contra esses desvios, haveria um verdadeiro lazer, carregado de positividade: ócio criativo, lazer sério, lazer ativo. Mas, por outro lado, não estariam essas categorias obstruindo o entendimento do fenômeno?

Se ao lazer é necessário serem emprestadas qualificações, é por que ele é um objeto plural, passível de muitos entendimentos ou por que, tal qual em um Teste de Rorschach cada autor projeta seus valores e expectativas sobre uma figura borrada? Talvez estejamos chegando ao momento de desconstrução do lazer como categoria acadêmica, pois como Rojek (1995), questionamos se o lazer se 
sustenta teoricamente como objeto de conhecimento, dada sua objetivação estar pautada em julgamentos de valor.

Essa assepsia lega ao lazer a prerrogativa de se afirmar como negação do tempo produtivo, sendo, pois ele é um tempo de nãotrabalho. Em complemento, ele é associado a conteúdos que preenchem sua existência, os quais não são concebidos em sua ambivalência. O lazer acaba por ser algo bom, funcional. No entanto, a abrangência em torno das práticas não-usuais desconsideradas como lazer, seria fulcral para o entendimento da possível identidade que se almeja dar ao lazer (ROJEK, 1995).

É importante frisar que não há equívoco em considerar que o lazer é um componente da qualidade de vida, sendo fundamental haver investimentos nesse campo da vida social (CSIKSZENTMIHALYI, 1999). Porém, justificar o lazer como algo bom, tal como um medicamento ou uma essência positiva reforçaria o moralismo sobre práticas não-usuais, tidas como patológicas. $\mathrm{O}$ lazer é um objeto estranho porque suas formas socialmente improdutivas são desqualificadas, como no caso do lazer passivo e as práticas moralmente reprováveis sequer chegam a serem incluídas como lazeres. Ora, se um fenômeno necessita ser bom e produtivo para ser considerado objeto, há limitação desse objeto ao subjetivismo de quem e com quais valores define o que é e não é lazer.

A esse respeito Rojek (2005) é um autor seminal ao ponderar que as ações humanas outrora tidas como boas ou ruins (portanto, um padrão moral) passaram, a partir do Século XVIII por um processo de leitura científica. Por meio das mesmas, foram desenvolvidos métodos e linguagens que tirassem a recriminação de condutas do campo religioso e dos costumes para um processo de "patologização", incluindo aí os lazeres. Logo, em exemplos, o consumo de álcool, assistir a um filme pornográfico, jogar um vídeo-game violento e praticar esportes de risco deixaram de ser fustigados apenas pela subjetividade afeita ao certo e errado e passaram ao exame dito objetivo da medicina, da psicologia e da psiquiatria, que podem diagnosticar essas opções (de lazer) como comportamentos desviantes, frutos de desequilíbrios e doenças. 
Eis que Rojek (2005) aponta para um paradoxo que merece nossa atenção em um debate sobre o lazer como questão de saúde. Para o autor, os próprios estudiosos do lazer criaram uma cilada para si, ao acatar ingenuamente essa patologização dos comportamentos desviantes. Se, como apontado anteriormente, o lazer é "vendido" como algo saudável, como podem certos lazeres estar associados a doenças? A solução dada foi a adjetivação do lazer, ampliando ainda mais sua irrelevância como categoria para se pensar as práticas no tempo livre. $\mathrm{O}$ objeto lazer foi reconduzido à sua condição etimológica de coisa lícita (licere em latim), empobrecendo a compreensão sobre esse fenômeno.

É importante frisar que Chris Rojek não advoga a legitimação de qualquer prática. Está preocupado com o esforço em se atribuir ao lazer apenas aspectos positivos, como se, por meio dele, também não ocorressem distúrbios, alienações, crimes, perversões e problemas de saúde pública. O lazer deve ser tratado, com imparcialidade (diferente de neutralidade), tendo os profissionais e estudiosos de estarem preparados tanto para suas benesses como para seus aspectos sombrios. Ademais, é imprescindível repensar sobre o lazer não apenas em termos do que seja hegemônico, pois até mesmo entendimentos supostamente enraizados, como lazer ativo ou passivo, podem estar sujeitos a resignificações diante das subjetividades contemporâneas.

Quanto à terminologia, é necessário ressaltar que tais vocábulos não apresentam uma linearidade. São termos datados. É perceptível sua força entre 1999 e 2009, com gradativo movimento de substituição pelo termo atividade (ou inatividade) física no lazer, como se pode verificar nas produções mais recentes (NAHAS et. al, 2010; DEL DUCA et. al, 2001; SILVA et. al., 2011). Terminologicamente esse recuo pode ter relação com as objeções públicas a seu uso ${ }^{2}$, buscando um conceito menos comprometedor. Mesmo no autor que difundiu o termo como um programa nas unidades brasileiras do

\footnotetext{
${ }^{2}$ Na programação de duas edições (2006 e 2009) do Encontro Nacional de Recreação e Lazer (ENAREL) esse termo foi assunto de calorosa discussão, demonstrando uma rejeição menos pelo termo que por seu uso restrito visando o estímulo à atividade física em contraponto ao sedentarismo.
} 
Serviço Social da Indústria, o uso de lazer passivo foi basicamente suprimido e lazer ativo vem passando a designar mais o programa, tendo a categoria se metamorfoseado em commodity para uso no meio não-acadêmico. Não obstante a tendência de caducarem tais termos, seus sentidos continuam sendo operados e continuam funcionando como movimentos institucionalizados.

\section{A CRUZADA do LAZER ATIVO}

Nos últimos anos está em evidência na Educação Física um discurso atualizado sobre ocupar o lazer com atividade física (lazer ativo), o qual propõe mudanças no estilo de vida: as pessoas deveriam fazer as atividades físicas que mais as agradassem no tempo livre e, em contrapartida, teriam uma vida mais saudável. A respeito dessas ideologias utilitárias, Stigger (2002) concorda que, embora reconheçam os outros aspectos, elas acabam associando a aquisição e desenvolvimento da saúde ao esporte de lazer, e tirando daí uma justificação poderosa para a sua prática.

Até o universo das atividades na natureza está envolvido pela idéia de atividade física no lazer como possibilidade de melhoria de alguns parâmetros relacionados à qualidade de vida. Como há uma crescente associação da aventura na natureza com a sensação de liberação de adrenalina e diminuição do estresse crônico, se evidencia tanto em publicações acadêmicas quanto na comercialização de pacotes turísticos a procura instrumental por essas práticas, o que vai desde spa em fazendas até cruzeiros marítimos com a temática fitness (PIMENTEL, 2006).

Há nessa vertente 'verde' do lazer ativo ainda a relação com os ditos "treinamentos empresariais". Spink, Medrado, Mello (2002, p. 163) chamam atenção para a possível relação entre o mundo globalizado e os esportes radicais, podendo os mesmos servir à formação de indivíduos para essa realidade. No plano discursivo, por exemplo, há presença de representações sociais sobre os esportes radicais serem, entre outras possibilidades, "ocasiões propícias para 
o desenvolvimento de funcionários mais flexíveis e aptos para operar adequadamente no âmbito do mercado globalizado".

Obviamente essa é uma pretensão mecânica e ingênua, pois desconsidera a resistência e as múltiplas apropriações que os sujeitos estabelecem com essas formas. Daí porque, mesmo com as diferentes seduções, o discurso do lazer ativo não supera as contradições. A primeira é que na história nunca se logrou um nível de produção e desenvolvimento econômico como o visto nos últimos 50 anos. Entretanto, essa revolução mostrou-se conservadora ao não dar conta nem da distribuição dos resultados dessa evolução como, também, muitos dos seus avanços repercutem mais que o lazer passivo nas doenças crônico-degenerativas.

Pode-se citar, por exemplo, desde a produção de alimentos calóricos sem valor nutritivo até a prioridade estatal e de mercado sobre os meios de transporte poluentes ao invés de políticas para o uso de bicicletas. Se, de fato, existisse um interesse em incentivar o estilo de vida ativo, alterações estruturais ocorreriam no mercado, mas, como visto, é o indivíduo, com seus hábitos, que sofre a coerção para mudar. Não está considerada nessa diretriz as causas do estresse no trabalho ou o tempo gasto no transporte, os quais têm efeito sobre o estado de ânimo desse trabalhador para um lazer com atividade física.

Destarte, o que se vê é o DNA do lazer ativo: um conceito ideológico, cunhado no funcionalismo, para uma intervenção neohigienista sobre as práticas desregradas do povo. Poderíamos ver nele ainda a reprodução da moralidade vigente, notadamente um ato de normalização disfarçada. Mas essa crítica isolada é facilmente vencida pela complexidade de fatores levados em consideração quando se promove o lazer ativo como uma categoria operativa dentro das novas tecnologias de gestão de pessoas. Se, por exemplo, já se criticou o reducionismo na recomendação de práticas corporais para a aptidão física, sem considerar a diversidade regional, a exclusão urbana e a opção pessoal, já se vê incorporação dessas variáveis na defesa do lazer ativo como sendo: 
[...] sentir-se bem na atividade escolhida, é realizar atividades que sejam culturalmente relevantes. Em Pomerode, Santa Catarina, tenho que fazer, promover, estimular bocha e o punhobol. São coisas culturalmente relevantes para aquelas comunidades. Bolão, boliche, etc. Não posso propor que eles caminhem, porque na cidade não há nem sistema de transporte urbano, todo mundo caminha e pedala para ir de um lugar a outro. O lazer ativo culturalmente relevante é aquilo que envolve o jogo, a dança, a diversão para essa comunidade. Para alguns trabalhadores da área urbana que passam sentados dez horas por dia, caminhar pode ser uma grande opção de lazer ativo, mas, obviamente, não é para todo mundo (NAHAS, 2005, p. 09).

Neste caso, é insuficiente caracterizar a cruzada em prol do lazer ativo como uma transparente moralização dos costumes via imposição. Entre outros olhares, funciona nesse discurso a construção, pelo poder, de conhecimentos e de verdades, entre os quais o lazer ativo seria uma benesse social a ser adotada como hábito das populações para seu próprio bem. Este aspecto é fundamental para entender que ações como o programa SESI Lazer Ativo não estão descontextualizadas. Há uma expressiva produção de saber que vai de dados estatísticos sobre o sedentarismo por setor laboral até os efeitos fisiológicos sobre a produtividade e qualidade de vida do operário, como salietam Nahas et. al. (2010). Ademais, não se destinam a um sujeito individualizado, mas à comunidade trabalhadora em geral, bem como seu background não é ingênuo, mas ciente, dos limites do exercício (ponderam, por exemplo, que a alimentação é um fator mais preponderante que a atividade física no combate à obesidade).

Assim, mesmo a categoria lazer ativo sendo controversa e carregada de valorações de juízo, que prejudicam sua acuidade acadêmica, os programas voltados para a prática de atividade física no tempo de não-trabalho aparentam-se altamente racionais e humanistas. Neste caso, há engano ao tomar o discurso da atividade física e saúde como destituído de referências socioculturais ou de reflexibilidade sobre seus limites. Aqui, parece necessário entender 
como um conceito sociocultural (lazer) assume operacionalidade a partir de uma rede discursiva entre as ciências exatas e biológicas.

Nesse caso, pode ser elucidativo se pensarmos, como Foucault (1997), que as que essa correlação de forças visa um caráter produtivo na sociedade. Para tanto, há uma confluência de novas técnicas, entre as quais a disciplinar é agregada pelo biopoder, a forma moderna dos governos lidarem com a difusão do poder e atingirem grandes contingentes. Logo, não se pensa mais no poder apenas como constrangimento individual, mas, sobretudo, como uma dinâmica voltada para desencadear e criar verdades e produtos destinados a manter a saúde das populações. Esse aspecto relacional, portanto, leva à incorporação das técnicas disciplinares junto às tecnologias políticas, que racionalizam a governamentalidade. Nisto, se destaca como tecnologia mais moderna o biopoder, refletido no cuidado sobre preservação da vida das populações (especialmente daqueles que mais precisarem: sedentários, desviantes, crianças), de tal forma que estes sejam também capazes de gerir em si as verdades necessárias para serem corpos saudáveis, felizes e produtivos.

$\mathrm{Na}$ estratégia moderna para governar os outros é fundamental, portanto, produzir conhecimentos que convençam a população sobre tais saberes e práticas visarem o bem. Se esses aspectos indicam a contradição em ser ativo no lazer, pois isso pode significar um corpo dócil diante de estratégias de despolitização do sujeito, a publicidade em torno do corpo belo e as campanhas de promoção da atividade física ancoradas nessa perspectiva são formas de sedução. Sedução no sentido que o poder é difuso entre sujeitos e instituições, sendo mais eficaz para qualquer ação de controle atrair que intimidar. Afinal, quantos já não se deixaram seduzir por um lazer ativo que, combatendo o lado passivo, devolverá o indivíduo ao seu bem-estar pleno? Não é, afinal, isso algo desejado e valorizado pela Educação Física? Pois, diante dos possíveis prazeres e benefícios, qual o problema de estar embutido no lazer ativo um estratagema?

Como a sabedoria ensina, a pergunta contém em si a resposta. Paradoxalmente, a busca em ser saudável pode representar uma 
forma de abdicação da liberdade e, de certa forma, do sentido da saúde. O aprisionamento a normas de qualidade de vida, pode comprometer o viver qualitativamente. Como provoca Maffesoli (1997), qualquer gado bem criado se encontra pleno de saúde, bem alimentado e consumidor da última moda, mas sem nunca ter acesso ao que qualifica um ser como sendo humano: ser livre.

\section{Considerações finAIS}

Na Educação Física existe uma constelação de autores e entidades que fazem defesas e proposições do lazer ativo na promoção da saúde. Todavia o termo não é uma exclusividade da área, obtendo adesão em outras disciplinas, como o Turismo, a Medicina, a Psicologia ou Urbanismo. Se, como vimos, essas relações utilitárias do termo remetem a uma possível gênese no funcionalismo, a gama de disciplinas a tratar do lazer ativo deve ao Higienismo uma de suas influências mais longevas.

As aproximações buscadas entre prática de atividades físicas e uso do tempo livre sugerem um movimento de justificação do "lazer ativo" em diferentes ambientes, tendo algumas argumentações, de cunho ideológico, assumido feições científicas. Em tal articulação, seus teóricos enfatizam a presença da obtenção da saúde nas atividades de lazer, com subsídios sobre o quanto isso implicaria em benefícios aos praticantes.

O limite desse tipo de leitura é o encadeamento mecânico de episódios, o que só pode fazer sentido numa perspectiva moralizante, na qual as boas ações geram bons resultados. Mas é necessário resgatar a aleatoriedade reinante no mundo físico, mesmo que o mundo social lhe empreste um sentido. Afinal, quanto se recomenda, por exemplo, a caminhada na perspectiva que isso resulte em saúde, por outro lado a pessoa pode ser atropelada enquanto atravessa uma rua. Portanto, assumir uma resposta em busca de melhorar a qualidade de vida, nos coloca em um mundo sujeito aos acasos. $\mathrm{O}$ lazer ativo não é uma garantia; é uma loteria: apostamos em uma série de comportamentos e práticas de lazer, buscando coisas boas, 
mas há em tudo certa indeterminação. Por isso, é essencial não olhar o lazer ativo e o lazer passivo como práticas que obrigatoriamente levarão a resultados opostos.

O passivo discursivo do lazer ativo pode ser encontrado na manipulação ideológica dessa categoria por instituições interessadas em reforçar a dimensão funcionalista das práticas no tempo livre. A visão higiênica aqui é predominante porque há uma evidente medicalização dos discursos, amparados por uma causalidade ingênua, pela qual basta o trabalhador aderir à atividade física para se resolver os problemas das doenças crônico-degenerativas. Certamente, os estudiosos da relação exercício físico e saúde não estão tomados por esse simplismo, mas contribuem para sua difusão no senso-comum quando empregam um lazer positivado como política de sedução. Nisto o moralismo preenche as lacunas interpretativas da suposta neutralidade positivista do lazer ativo.

Se, nesse raciocínio pelo qual foi construído, o lazer é uma condição da sociedade industrial e é possível encontrar nele uma função de harmonização social e promoção da saúde é porque a vida como um todo possui uma missão edificante a cumprir. Ora, se os meios estão disponíveis, cada indivíduo que não emprega seu tempo livre para ser "ativo" não apenas deixa de cumprir o sentido transcendente do lazer, determinado pela ordem das coisas, mas, também, peca contra si mesmo e a sociedade. Em nos fazer acreditar nessa falácia e reproduzi-la em nossas práticas sociais e acadêmicas reside a genialidade desses poderes estatais e paraestatais que operam com a fusão de mecanismos de controle e biopoder. 
The passive of the active leisure

Abstract: The term active leisure has been used to define free-time physical activity. This paper analyzes this category from the following topics: the sayings and writings about active leisure in the academic environment; its relation to positivism and functionalism; the popularization of the term within the network of discourses aimed at biomedical control of free time made by population.

Keywords: Leisure Activities. Health. Power.

\section{El pasivo de el ocio activo}

Resumen: El ocio activo es una palabra utilizada para definir la actividad física durante el tiempo libre. Este texto hace crítica de la categoría, utilizando como tópicos de análisis: los dichos y escritos acerca del ocio activo en el ámbito académico; su relación con el positivismo y el funcionalismo; la popularización del término en la red de representaciones e acciones biomédicas de control del tiempo libre de la populación. Palabras clave: Actividades Recreativas. Salud. Poder.

\section{REFERÊNCIAS}

BACKMAN, S. J.; CROMPTON, J. L. Differentiating between active and passive discontinuers of two leisure activities. Journal of Leisure Research, Washington, v. 22, n. 3, p. 197-212, 1990.

COURTINE, J. J. Os stakhanovistas do narcisismo: Bodybuilding e puritanismo ostentatório na cultura americana do corpo. In: SANT'ANNA, D. B. (Org.). Políticas do corpo: Elementos para uma história das práticas corporais. São Paulo: Estação Liberdade, 1995. p. 81-114.

CSIKSZENTMIHALYI, M. A descoberta do fluxo: a psicologia do envolvimento com a vida cotidiana. Rio de Janeiro: Rocco, 1999.

DEL DUCA, G. F; OLIVEIRA, E. S. A. ; SOUSA, T. F.; SILVA, K. S.; NAHAS, M. V. Inatividade física no lazer em trabalhadores da indústria do Rio Grande do Sul, Brasil. Motriz, Rio Claro, v. 17, p. 180-188, 2011.

DIAS, C. A. G. Teorias do lazer e positivismo. In: PIMENTEL, G. G. de A. (Org.). Teorias do lazer. 1. reimp. Maringá - PR: Eduem, 2011, p. 43-73.

FOUCAULT, M. As palavras e as coisas. São Paulo, Martins Fontes, 2002. 
FOUCAULT, M. Resumo dos cursos do College de France 1970-1982. Rio de Janeiro: Zahar, 1997.

FRAGA, A. B. Exercício da informação: governo dos corpos no mercado da vida ativa. Campinas: Autores Associados, 2006.

GUEDES, D. P. et. al. Níveis de prática de atividade física habitual em adolescentes. Revista Brasileira de Medicina do Esporte, São Paulo, v. 7, n.6, p. 187-199, 2001.

GURGEL, A. Saúde simples e eficaz. Londrina - PR: Líder, 2002.

HELMAN, C. G. Cultura, saúde e doença. 4 ed. Porto Alegre: Artmed, 2003.

HOOD, B. M. Supersentido: porque acreditamos no inacreditável. Ribeirão Preto - SP: Novo Conceito, 2010.

MAFFESOLI, M. A transfiguração do político: a tribalização do mundo. 2. ed. Porto Alegre: Sulina, 1997.

MANIFESTO de São Paulo para a promoção da atividade física nas Américas. Revista Brasileira de Ciências da Saúde, São Caetano do Sul, v. 01, n. 01. p. 70-71, jan/jun. de 2003.

MELO, V. A. de. Lazer, Animação Cultural e Cinema: os comentários cinematográficos. Licere, Belo Horizonte, v. 8, n. 1, p. 93-110, 2005.

NAHAS, M. V. Painel 1: Experiências de organizações sociais em programas de saúde e lazer por meio de atividades físicas e esportes. In: SEMINÁRIO INTERNACIONAL VIDA ATIVA E AÇÃO COMUNITÁRIA. Anais....Sesc: São Paulo, 2005.

NAHAS, M. V.; BARROS, M. V. G.; OLIVEIRA, E. S. A.; SIMM, E. E.; ANTONY, G. Lazer Ativo: um programa de promoção de estilos de vida ativos e saudáveis para o trabalhador da indústria. Revista Brasileira de Atividade Física e Saúde, Londrina, v. 15, p. 260-264, 2010.

PIMENTEL, G. G. de A. Sobre os desvios no lazer: questões para se pensar a corrupção do lúdico. In: LARA, L. M. (Org.). Abordagens socioculturais em educação física. Maringá: Eduem, 2010, p. 81-112.

PIMENTEL. G. G. de A. Aventuras de lazer na natureza: o que buscar nelas? In: MARINHO, A.; BRUHNS, H. T. (Orgs.). Viagens, lazer e esporte. Barueri: Manole, 2006. p. 43-73.

ROJEK, C. Decentring leisure: rethinking leisure theory. Great Britain: SAGE, 1995.

ROJEK, C. Leisure theory: principles and practice. Great Britain: Paulgrave, 2005. 
SILVA, S.G.; SILVA, M. C; NAHAS, M. V; VIANA, S.L. Fatores associados à inatividade física no lazer e principais barreiras na percepção de trabalhadores da indústria do sul do Brasil. Cadernos de Saúde Pública, Rio de Janeiro, v. 27, p. 249-259, 2011.

SPINK, M. J.; MEDRADO, B.; MÉLLO, R. P. Perigo, probabilidade e oportunidade: a linguagem dos riscos na mídia. Psicologia Reflexão e Crítica, Porto Alegre, v. 15, n. 1, p. 151-164, 2002.

STIGGER, M. P. Esporte, lazer e estilos de vida: um estudo etnográfico. Campinas: Autores Associados, 2002.

TUBINO, M.J. G. Fiep and the World Summit on Physical Education. The FIEP Bulletin, v. 7, p. 2-8, 2007.

Endereço para correspondência

Universidade Estadual de Maringá,

Centro de Ciências Biológicas,

Departamento de Educação Física.

Av. Colombo, n. 5790, Zona 07,

CEP 87020-900 Maringa, PR - Brasil

Recebido em: 31.07.2011

Aprovado em: 03.09.2012

Movimento, Porto Alegre, v. 18, n. 03, p. 299-316, jul/jset de 2012. 
